\title{
Pigmented (Melanotic) Neurofibroma. Report of an Unusual Case with Immunohistochemical, Ultrastructural and Cytogenetic Analyses
}

\author{
Cornelius Kuhnen ${ }^{1}$, Peter Herter ${ }^{2}$, Christian Soimaru $^{3}$, \\ Heinz-Herbert Homann ${ }^{3}$, Georg Johnen ${ }^{1}$ \\ 'Institute of Pathology, Limb Tumor Registry, University Hospital Bergmannsheil, \\ Bochum, Germany \\ ${ }^{2}$ Max-Planck Institute of Molecular Physiology, Dortmund, Germany \\ ${ }^{3}$ Department of Plastic and Hand Surgery-Burn Center, Limb Tumor Registry, \\ University Hospital Bergmannsheil, Bochum, Germany
}

\section{Summary}

In the spectrum of neurofibromas, pigmented tumors are rare variants usually showing only faint, macroscopically obvious pigmentation. We report a case of a huge pigmented neurofibroma with extended, macroscopically striking pigmentation in a patient with stigmata of neurofibromatosis. The immunohistochemical and ultrastructural findings support a melanotic line of differentiation besides schwann cell differentiation and indicate a phenotypic neoplastic spectrum between tumorous schwann cells and melanocytes. Using comparative genomic hybridization, striking chromosomal aberrations were not detected. High level amplifications of the known chromosomal regions, including genes of major enzymes responsible for melanin synthesis, appear to be unlikely. However, smaller chromosomal defects might have been overlooked by the limited resolution of this screening method. Therefore, other mechanisms up-regulating melanogenesis, such as mutations in regulatory genes, have to be considered.

Key words: Pigmented neurofibroma - Soft tissue tumor - Comparative genomic hybridization

\section{Introduction}

Pigmented (melanotic) neurofibroma is a rare variant of neurofibroma, with only a limited number of cases re- ported to date. As in melanotic schwannoma, this tumor has the ability to synthesize melanin [2] as do different cells derived from the neural crest (e.g. nevomelanocytes, nerve sheath cells).

We present a case of an unusually huge pigmented neurofibroma in neurofibromatosis, including immunohistochemical, ultrastructural and cytogenetic findings. Comparative genomic hybridization was used to discover further indications of chromosomal aberrations that might lead to stimulation in melanogenesis.

\section{Case Report}

Clinical history. Darker pigmentation of the entire lower left arm with extension to the elbow region and the adjacent upper arm has been evident since birth of the 41 -year-old male patient. At the age of 18 , he noticed a continuous enlargement of adjacent soft tissues. He underwent partial resection of the lesion twice at the age of 25 (1984, Syria) and 31 (1990, Lebanon). The soft tissue tumor could not be resected at that time because of considerable bleeding. Neither in 1984 nor in 1990 were

Address for correspondence: Cornelius Kuhnen, Institute of Pathology, Limb tumor registry, University Hospital Bergmannsheil, Bürkle-de-la-Camp-Platz 1, D-44789 Bochum, Germany.

Tel.: +49-(0)234/302-6600; Fax: +49-(0)234/302-6671;

E-mail: patho-bhl@ruhr-uni-bochum.de. 
histopathological examinations done. The patient presented with swelling of the entire lower left arm, circumference approximately $50 \mathrm{~cm}$, and exaggerated pigmentation of the skin overlying the tumor without hypertrichosis (Fig. 1A). The uninvolved skin showed slightly tan, but no comparable hyperpigmented color. There was no evidence of motoric or clearly sensoric impairment of the extremity, but the patient complained about considerable swelling of the lesion after work and exposure to cold. Using magnetic resonance imaging, the lesion was reminiscent of hemangioma or lymphangioma. Physical examination revealed more than six cutaneous café-aulait-spots on the thorax, back, left buttock and in the supraorbital region, extending $1.5 \mathrm{~cm}$ in diameter. In addition to the soft tissue tumor of the left lower arm, a small neurofibroma of the back skin located within a café-au-lait-spot was found. There were no other stigmata of the neurofibromatosis complex, such as axillary freckling, Lisch nodules, optic glioma, dysplastic lesions of bones, or a first-degree relative with neurofibromatosis 1 . Because of the large tumor size, an initial partial resection ("debulking") was done, removing approximately one fourth of the tumor mass.

Following gross and microscopical examination of the lesion, pigmented neurofibroma was diagnosed. The number of café-au-lait-spots and neurofibromas confirmed the diagnosis of neurofibromatosis 1 .

\section{Materials and Methods}

Freshly-obtained tumor tissue of the surgical specimen was snap-frozen in liquid nitrogen for further genetic analysis and fixed in glutaraldehyde for ultrastructural analysis. Following photographic documentation, the specimen was fixed in $4 \%$ buffered formalin solution and paraffin-embedded. Sections (3-5 $\mu \mathrm{m}$ thick) were stained with hematoxylin and eosin (HE).

Immunohistochemistry was performed on selected paraffin sections using a standard APAAP (alkaline phosphatase anti alkaline phosphatase) method as described elsewhere [9]. Antibodies against the following antigens were used: S-100 protein (Dako, polyclonal, 1:6000), melan A (Biogenex, clone A 103, dilution 1:800), tyrosinase (Novocastra, clone T11, 1:50), gp 100 (Biogenex, clone HMB 45, 1:50), microphthalmia transcription factor (NeoMarkers, clone C5+D5, 1:25), neurofilaments (Dako, clone 2F11, 1:100), CD34 (Im- munotech, clone QBEND10, 1:4000), CD57 (Novocastra, clone HNK-1, 1:100), EMA (Dako, clone E29, 1:50), Ki 67 (Dianova, clone MIB-1, 1:60).

For transmission electron microscopy (TEM), small pieces of tumor tissue were fixed with $2.5 \%$ glutaraldehyde and postfixed with $1 \%$ osmium tetroxide, degraded in an ascending series of ethanol, processed through propylene oxide, and embedded in epoxy resin. Semithin sections were stained with toluidine blue, and appropriate areas were selected for the study of ultrastructure. To improve contrast, ultrathin sections were stained with uranyl acetate followed by lead citrate and then investigated with a ZEISS 902 electron microscope. The melanosomal structures were characterized according to the criteria proposed by Erlandson [1].

Comparative genomic hybridization ( $\mathrm{CGH}$ ) was carried out as described elsewhere [8]. The software package Quips (Vysis, owners Grove, IL) was used for evaluating CGH data.

\section{Pathological findings}

\section{Gross findings}

Partial tumor resection resulted in three skin/soft tissue portions with a total weight of $1005 \mathrm{~g}$. Tumor size was $39 \times 15.5 \times 5 \mathrm{~cm}$ in greatest dimension with "plate-like" extension within the superficial soft tissues, i.e., within the subcutaneous fat between dermis and superficial fascia. The lesion showed a slight rubbery consistency with glistening cut surface. Besides gray-white colored areas, the tumor cut surface showed a prominent irregularly configurated gray-black coloration extending beyond the entire specimen, intermingled with the more whitecolored regions, giving a mottled appearance. The tumor margins were ill-defined (Fig. 1B).

\section{Microscopic, immunohistochemical findings}

The lesion showed poorly-defined tumor margins with infiltration of subcutaneous fatty tissue and entrapment of skin adnexa (Fig. 1C). Neither infiltration of skeletal muscle nor junctional cellular (nevomelanocytic) component/activity was noted. Elongated fusiform spindle cells and plump oval to round shaped cells were set in a loose collageneous, partly myxocollageneous matrix. In general, the tumor showed moderately cellular appearance. Apart from the more spindle-shaped cells, areas

Fig. 1. A: Clinical finding of hyperpigmented skin of the entire left forearm overlying an extended soft tissue mass. Notice the non-affected right forearm (patient in upright position). B: Cut surface of pigmented neurofibroma specimen: diffusely-extended, soft tissue mass within the superficial soft tissues showing an irregularly-configurated, gray-black coloration. Tumor size in this photograph: $12.5 \times 5 \mathrm{~cm}$. C: Permeation of adipose tissue by tumor cells. D: Apart from spindle-shaped, fusiform and curved nuclei, small aggregates of plumper and rounded nuclei of tumor cells without nuclear atypia are evident (loose collageneous background). E: Single Wagner-Meissner body-like structures within the tumor tissue. F: Finely and coarsely-distributed, dark-brown pigment predominantly located in small aggregates of plumper and rounded cells apart from extracellular pigment distribution. G: S-100 immunoreactivity of tumor cells with staining of cytoplasm, particularly dendritic processes, and focal nuclear staining. H: Nuclear staining with antibody against microphthalmia transcription factor. 

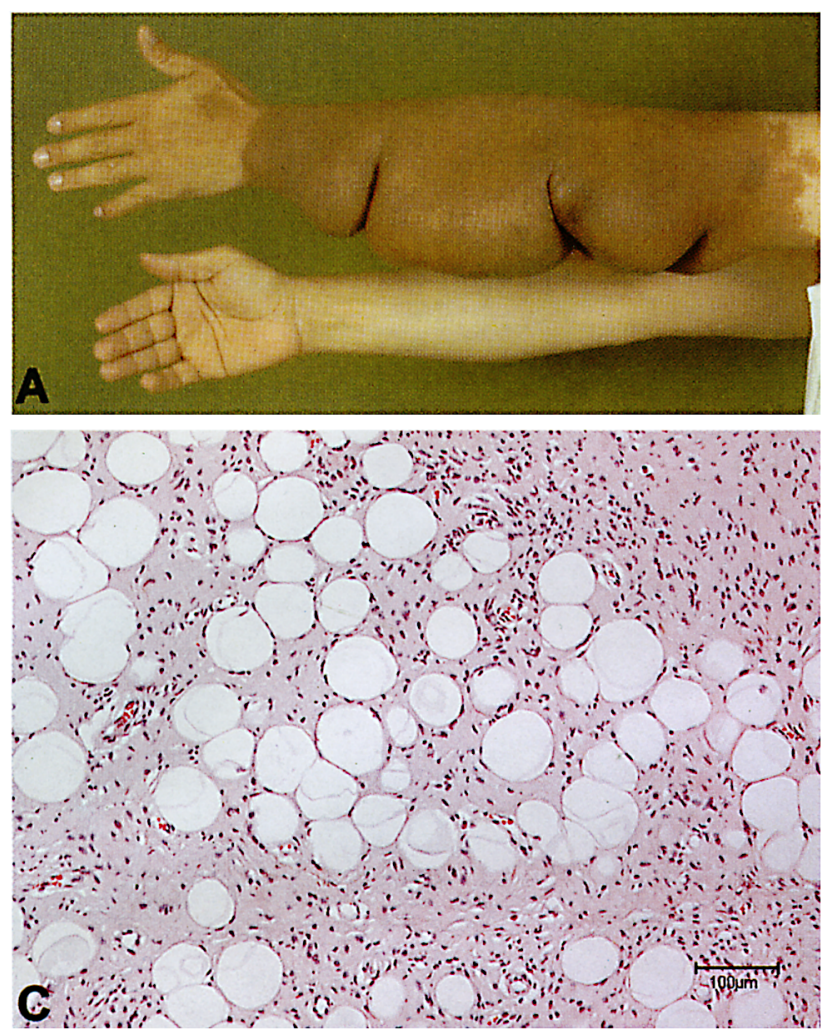

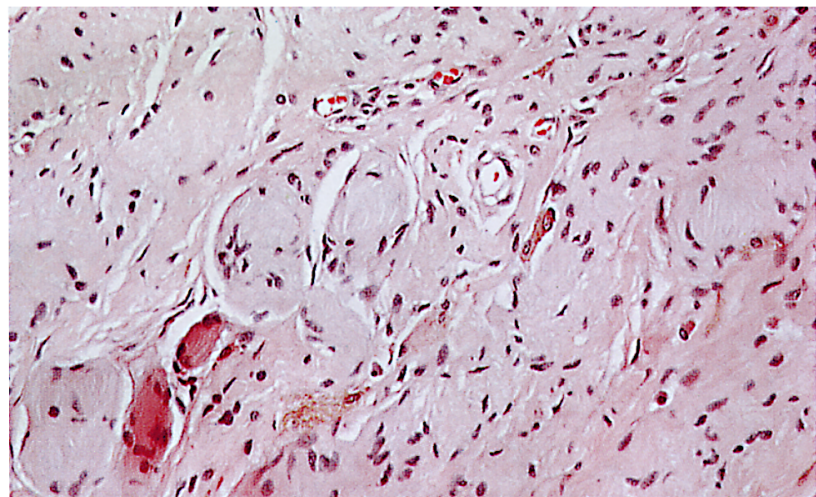

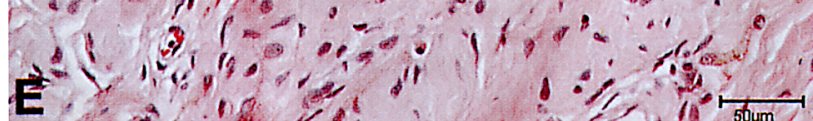

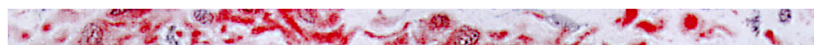

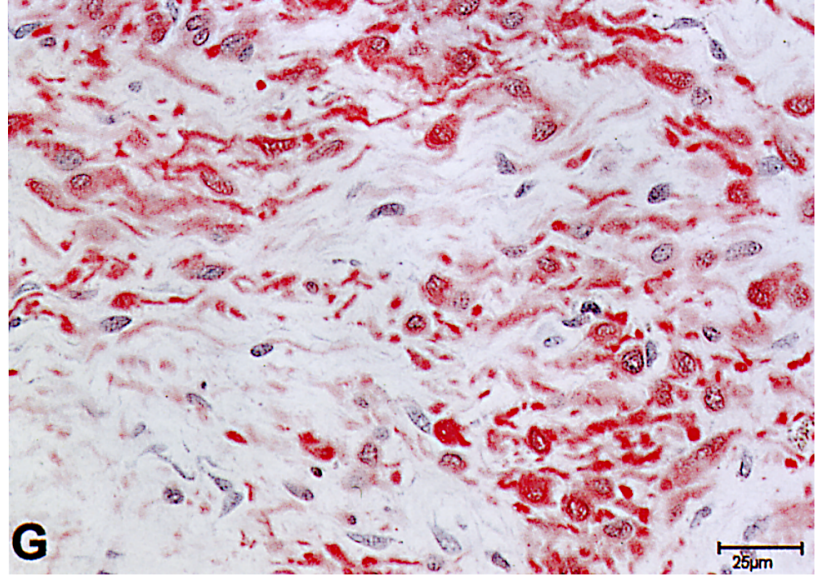
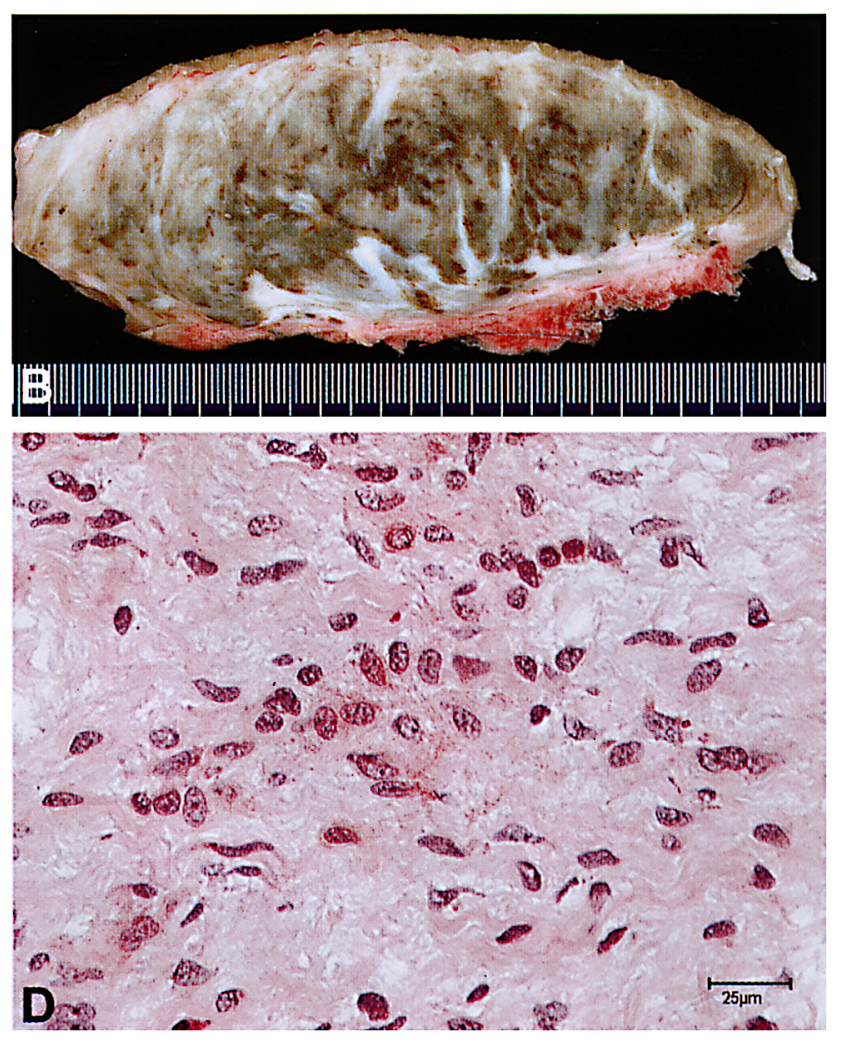

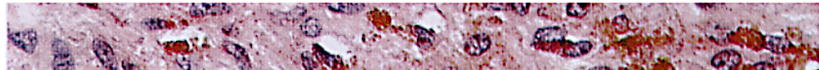

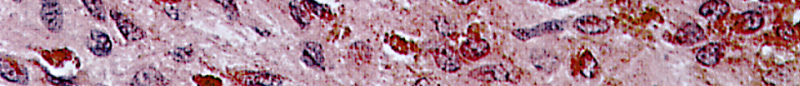

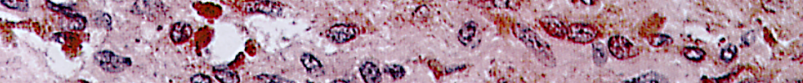

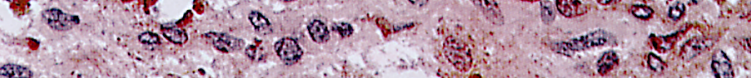

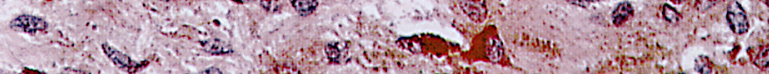

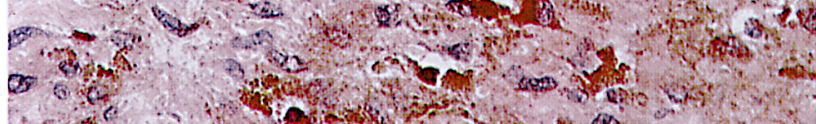

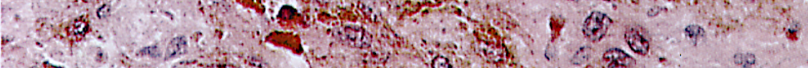

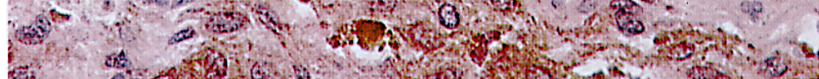

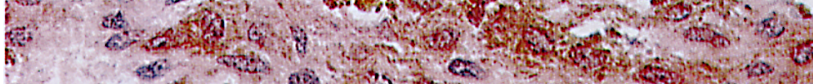

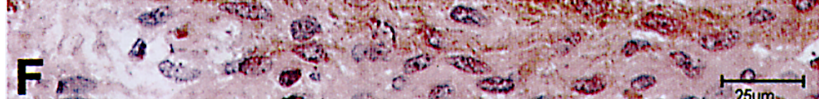

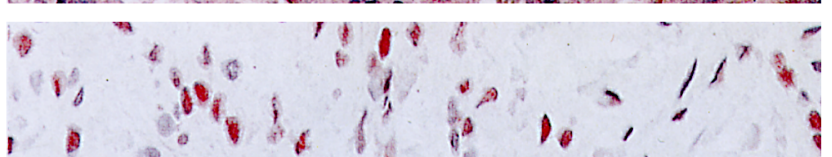

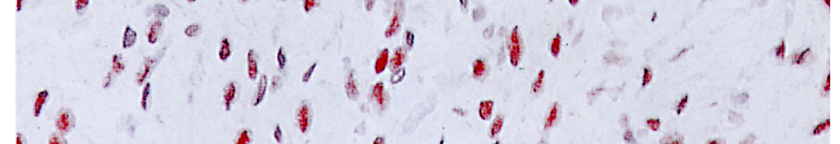

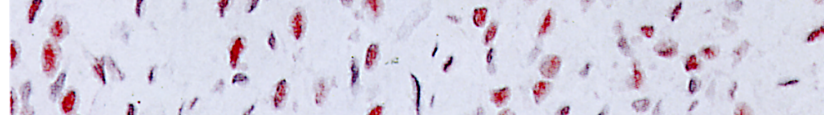

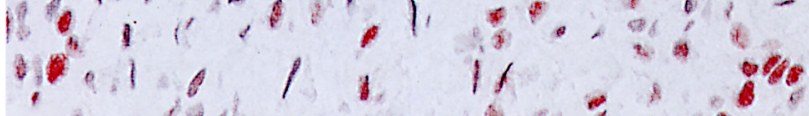

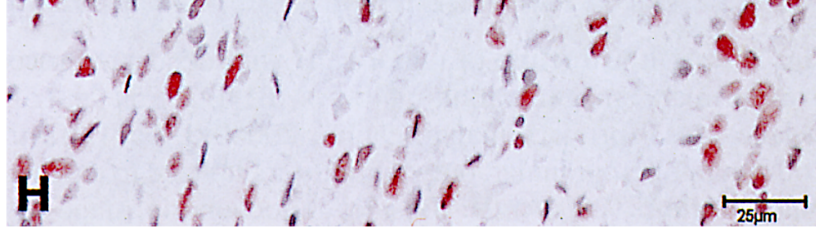


containing loose clusters and aggregates of plumper and even epithelioid cells were evident. These regions were evenly distributed within the tumor. The tumor cells were characterized by ill-defined cellular margins with slightly eosinophilic cytoplasm and inconspicious, often curved nuclei without atypia (Fig. 1D). No calcifications were encountered. The mitotic rate was less than 1 per $50 \mathrm{HPF}(\times 40)$. Single Wagner-Meissner-like bodies were detected particularly in the peripheral parts of the lesion, underlining the overall appearance of a diffuse neurofibroma (Fig. 1E). Numerous mast cells were detected within the tumor tissue. Overall, there was no evidence of increased cellularity, mitotic activity or atypia indicating malignant transformation.
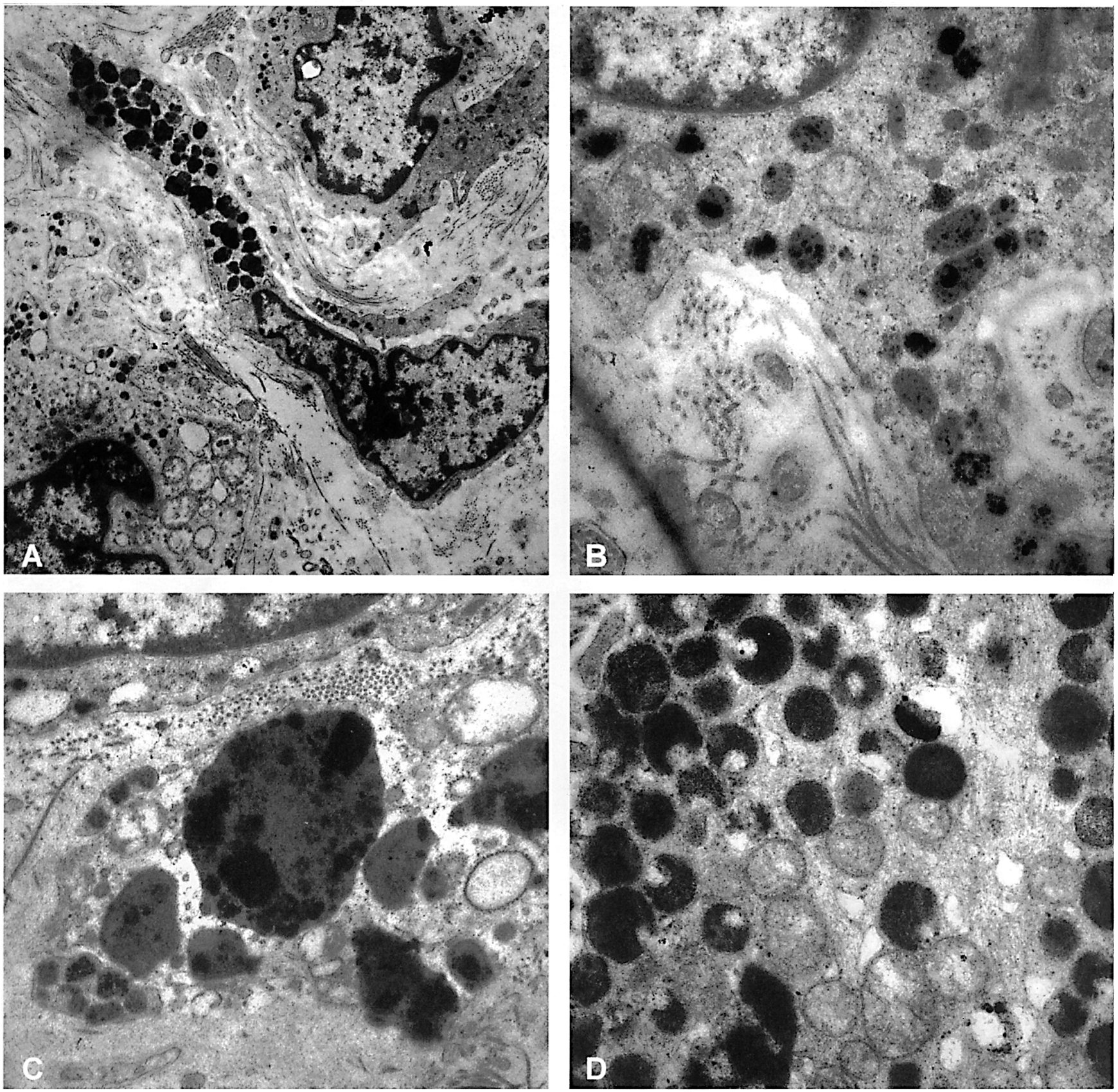

Fig. 2. A: Ultrastructure of tumor cells with dendritic processes containing electron-dense melanosomal organelles of varying size (primary magnification: 4400x). B: Electron microscopy showing small aberrant microgranular, partly-melanized melanosomes (primary magnification: 20000x). C: Ultrastructure of a wide variety of aberrant melanosomal configurations from small microgranular, only partially-melanized to extended, irregularly-shaped, nearly fully electron-dense vesicles (primary magnification: 12000x). D: Besides mitochondria, stage III-IV mature melanosomes with homogeneously electron-dense and rounded structures (primary magnification: $20000 \times$ ). 
Finely and coarsely granular dark-brown pigment was found particularly within plumper epithelioid cells and, to a lesser extent, within the spindle-shaped cells showing predominantly curved nuclear profiles (Fig. $1 F)$. Pigment was also detected within the extracellular space distributed in a "dusty" matter. Using iron-formelanin- and prussian-blue-stainings, the pigment was highlighted as melanin.

Immunohistochemically, the tumor cells were diffusely reactive for S-100 protein (Fig. $1 \mathrm{G}$ ), focally positive for melan-A, and only focally and faintly positive for tyrosinase. There was no reactivity with antibody HMB-45. Approximately $40 \%$ of the tumor cells showed positive nuclear staining for microphthalmia transcription factor (Fig. 1H). Some cells revealed faint cytoplasmic reactivity against $\mathrm{CD} 34$ and $\mathrm{CD} 57$, the tumor cells were negative for EMA. Clear structures reminiscent of neuritic processes were not evident using an antibody against neurofilaments. No proliferative activity was noted using antibody MIB-1.

\section{Ultrastructural findings}

Ultrastructurally, the tumor cells contained electrondense melanosomal organelles. Most of these could be characterized as spherical vesicles, their size ranging from electron-dense microgranules (Figs. $2 \mathrm{~A}, \mathrm{~B}$ ) to fully melanized inclusions (Fig. 2C). In summary, the differently-sized organelles were classified as aberrant melanosomes. Apart from these, stage III-IV mature melanosomes with homogeneously electron-dense and rounded structures were evident (Fig. 2D).

\section{Final diagnosis:}

Pigmented (melanotic) diffuse neurofibroma in neurofibromatosis 1 .

\section{Comparative genomic hybridization}

The analysis revealed a normal karyotype without chromosomal aberrations. Aberrations, including the regions $9 q, 11 q$ or $12 q$ (gene loci for enzymes dopamine- $\beta$-hydroxylase, tyrosinase, phenylalanine hydroxylase) [7], were detected (Fig. 3).

\section{Discussion}

\section{Concept of pigmented neurofibroma}

This case of a melanotic neurofibroma is characterized by an exuberant, even macroscopically striking pigmen-
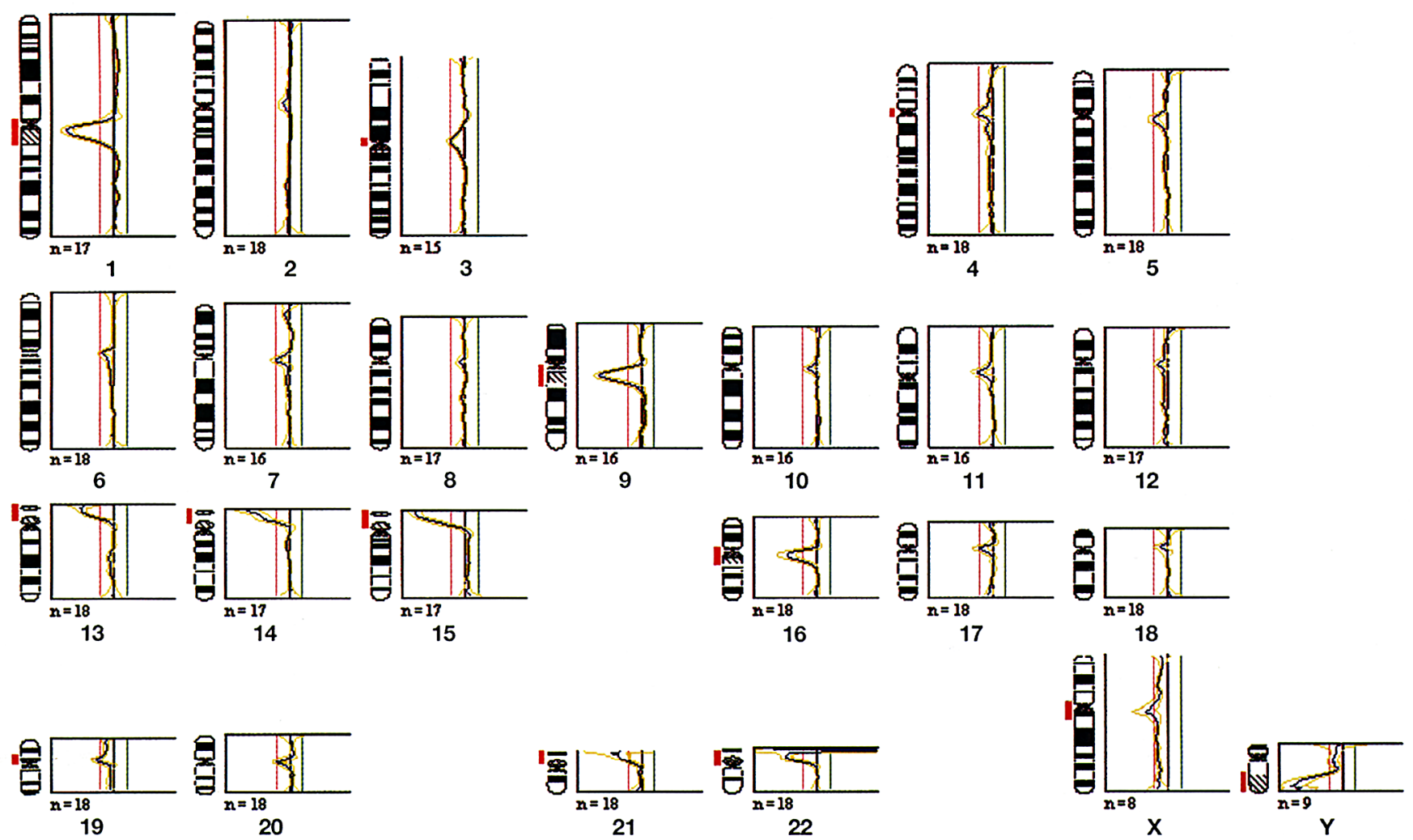

Fig. 3. CGH sum karyogram. The neurofibroma examined shows a normal karyotype. The ratio profiles of all chromosomes are almost normal (black lines, set to 1.0) and within the threshold limits for losses (red lines, set to 0.8) and gains (green lines, set to 1.2). All visible losses, depicted as red bars with a ratio profile below 0.8 , are within known artifact regions, e.g. heterochromatin in centromers and the long arm of chromosome $\mathrm{Y}$, that are excluded from the evaluation. 
tation within huge tumor dimensions. In the majority of documented pigmented neurofibromas, grossly dominant melanotic coloration was either absent or an unusual finding [17]; in a larger series reported by Fetsch et al, only $16 \%(3 / 19)$ of the tumors investigated revealed macroscopically detectable areas of pigmentation [2]

It still needs to be clarified whether the marked cutaneous hyperpigmentation in this case of melanotic neurofibroma in a patient with neurofibromatosis may be regarded as an indicator of a general "neurocutaneous dysplasia" in the patient's extremity. Increased melanogenesis was observed in cultured epidermal melanocytes from patients with neurofibromatosis 1 [6]. To explain melanotic pigmentation in neurofibromas, it is noteworthy that these tumors show a clear predeliction for occurring in dark-skinned individuals [2]. The reason for this remains unclear. An accumulation of displaced melanocytes during embryonal development and of schwann cells with melanogenesis has to be considered. In summary, a phenotypic "overlap" between schwann cells and melanocytes in such tumorous lesions can be assumed, particularly in view of a common neural crest origin of these cell types [2]. The detection of microphthalmia transcription factor in the nuclei of tumor cells of the pigmented neurofibroma described further underlines this close phenotypic relationship between melanin-producing schwann cells and melanocytes, as this transcription factor is essential for the development and survival of melanocytes [14].

\section{Related pigmented tumorous lesions of the skin and soft tissue and differential diagnosis}

Some tumors of the skin and soft tissue have to be considered in the differential diagnosis of pigmented neurofibroma. These include the (giant) congenital nevus with neuroid features (neuronevus), the so-called neurocristic cutaneous hamartoma, melanotic schwannoma, blue nevus, and Bednár tumor. Strict criteria differenting between pigmented neurofibroma on the one hand and congenital neuronevus and neurocristic cutaneous hamartoma on the other hand are difficult to establish because the two latter "entities" reported in the literature are of variable morphology $[4,10,12,15]$. In contrast to neurofibroma and congenital nevus, the so-called neurocristic cutaneous hamartoma typically exhibits neither a predominant neurofibroma growth pattern nor a clear junctional nevomelanocytic compartment [15]. Melanotic schwannomas are usually encapsulated tumors with a predeliction for spinal roots. The richly pigmented tumor cells have a fusiform or epithelioid shape, often showing more vesicular nuclei and prominent nucleoli, which usually cannot be found in neurofibroma $[2,5]$. The typical neurofibromatous architecture is lacking. The blue nevus in its cellular variant is characterized by spindle cells involving the reticular dermis [11]. In con- trast to this case of pigmented neurofibroma, such huge dimensions are usually not expected in blue nevus, nor are Wagner-Meissner-like bodies found. Bednár-tumor is predominantly located on the trunk and shows the characteristic histological features of DFSP as well as a strong immunoreactivity with antibodies against CD 34 . The pigmented cells in Bednár-tumor may be immunoreactive for S-100-protein [3].

\section{Cytogenetics of pigmented neurofibroma}

The loci of phenylalanine hydroxylase (12q24.1, phenylalanine catabolism), dopamine-beta-hydroxylase (9q34, catecholamine biosynthesis), and tyrosinase (11q14-21) have been linked to melanotic tumors. In view of the fact that phenylalanine hydroxylase and dopamine-beta-hydroxylase are normally not involved in melanin formation, an abnormal biosynthetic role for these enzymes has been suggested [7]. The CGH results, however, show no larger chromosomal defects in this tumor, including the above-mentioned loci. Although chromosomal losses smaller than ten mega basepairs usually cannot be detected with the CGH method, detection of high-level amplifications of smaller regions is possible. It is therefore more likely that smaller mutations in regulating genes might have occurred rather than gene amplifications of biosynthetic enzymes. Indeed, the immunohistochemical results show that microphthalmia transcription factor, which regulates tyrosinase expression [16], is convincingly positive in the tumor tissue. An examination of genes upstream in the transcriptional hierarchy, e.g. SOX10 and PAX3, should be conducted in future investigations [13].

Acknowledgments. The authors gratefully acknowledge the excellent technical assistance of Malgorzata Jaworska, Ph.D., Susanne Schaub-Kuhnen (Institute of Pathology, University Hospital Bergmannsheil, Bochum) and Alice Kasprzynski (Max-Planck-Institute of Molecular Physiology, Dortmund).

\section{References:}

1. Erlandson RA (1994) Diagnostic transmission electron microscopy of tumors. Raven Press, New York

2. Fetsch JF, Michal M, Miettinen M (2000) Pigmented (melanotic) neurofibroma: a clinicopathologic and immunohistochemical analysis of 19 lesions from 17 patients. Am J Surg Pathol 24: 331-343

3. Fletcher CDM, Theaker JM, Flanagan A, Krausz T (1988) Pigmented dermatofibrosarcoma protuberans (Bednar tumor): melanócytic colonization or neuroectodermal differentiation? A clinicopathological and immunohistochemical study. Histopathology 13: 631-643

4. Hendrickson MR, Ross JC (1981) Neoplasms arising in congenital giant nevi. Morphologic study of seven cases and a review of the literature. Am J Surg Pathol 5: 109-135 
5. Katenkamp D, Filippowa N, Raikhlin NT (1986) Das melanozytische Schwannom. Licht- und elektronenmikroskopische Befunde zur Morphologie, Diagnose und Differentialdiagnose. Zentralbl Allg Pathol Pathol Anat 131: $107-118$

6. Kaufmann D, Wiandt S, Veser J, Krone W (1991) Increased melanogenesis in cultured epidermal melanocytes from patients with neurofibromatosis 1 (NF1). Hum Genet 87: 144-150

7. Kimura N, Watanabe M, Date F, Kitamoto T, Kimura I, Horii A, Nagura H (1997) HMB-45 and tuberin in hamartomas associated with tuberous sclerosis. Mod Pathol 10: 952-959

8. Krismann M, Adams H, Jaworska M, Müller K-M, Johnen G (2000) Patterns of chromosomal imbalances in benign solitary fibrous tumours of the pleura. Virchows Arch 437: 248-255

9. Kuhnen C, Herter P, Müller O, Muehlberger T, Krause L, Homann H, Steinau HU, Müller K-M (2000) B-Catenin in soft tissue sarcomas: expression is related to proliferative activity in high-grade sarcomas. Mod Pathol 13: 1005-1013

10. Mezebish D, Smith K, Williams K, Menon P, Crittenden J, Skelton H (1998) Neurocristic cutaneous hamartoma: a distinctive dermal melanocytosis with an unknown malignant potential. Mod Pathol 11:573-578

11. Misago N (2000) The relationship between melanocytes and peripheral nerve sheath cells (part II): blue nevus with peripheral nerve sheath differentiation. Am J Dermatopathol 22: 230-236
12. Pearson JP, Weiss SW, Headington JT (1996) Cutaneous malignant melanotic neurocristic tumors arising in neurocristic hamartomas. A melanocytic tumor morphologically and biologically distinct from common melanoma. Am J Surg Pathol 20: 665-677

13. Potterf SB, Furumura M, Dunn KJ, Arnheiter H, Pavan WJ (2000) Transcription factor hierarchy in Waardenburg syndrome: regulation of MITF expression by SOX 10 and PAX3. Hum Genet 107: 1-6

14. Shibahara S, Yasumoto K, Amae S, Udono T, Watanebe K, Saito H, Takeda K (2000) Regulation of pigment cellspecific gene expression by MITF. Pigment Cell Res 13 (Suppl 8): 98-102

15. Smith KJ, Mezebish D, Williams J, Elgart ML, Skelton HG (1998) The spectrum of neurocristic cutaneous hamartoma: clinicopathologic and immunohistochemical study of three cases. Ann Diagn Pathol 2: 213-223

16. Tachibana M, Takeda K, Nobukuni Y, Urabe K, Long JE, Meyers KA, Aaronson SA, Miki T (1996) Ectopic expression of MITF, a gene for Waardenburg syndrome type 2, converts fibroblasts to cells with melanocyte characteristics. Nat Genet 14: 50-54

17. Weiss SW, Goldblum JR (2001) Enzinger and Weiss's soft tissue tumors, $4^{\text {th }}$ edn. Mosby, St. Louis London Philadelphia

Received: November 13, 2001

Accepted in revised version: January 8, 2002 